\title{
What if we lose a hub? Experimental testing of pollination network resilience to removal of keystone floral resources
}

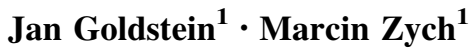

Received: 8 November 2015/Accepted: 24 March 2016/Published online: 2 April 2016

(c) The Author(s) 2016. This article is published with open access at Springerlink.com

\begin{abstract}
On the basis of theoretical predictions, pollination networks seem to be resilient to random node elimination but sensitive to targeted exclusion. However, such predictions have a very weak empirical basis. In order to test the robustness of the pollination network to shortterm disturbances, we removed inflorescences of the most connected species occurring in a lowland meadow network using the before-after approach and compared the result with that obtained by network modelling. The manipulated network showed no significant differences for the most commonly used metrics, but was more generalized than control networks, owing to a change in the preferences of pollinators. Furthermore, no secondary extinctions (emigrations) were found, owing to the considerable natural variation found among insect species assemblages. Following elimination of the most linked plant species, a new hub was detected in the experimental meadow, the hub node being a plant species with a similar inflorescence to that removed, and formerly playing the role of a peripheral node. We conclude that exclusion of the main food source forced insects to change their specialized preferences to
\end{abstract}

Handling Editor: Heikki Hokkanen.

Electronic supplementary material The online version of this article (doi:10.1007/s11829-016-9431-2) contains supplementary material, which is available to authorized users.

Jan Goldstein

j.goldstein@biol.uw.edu.pl

Marcin Zych

mzych@biol.uw.edu.pl

1 Faculty of Biology, University of Warsaw, Botanic Garden, Al. Ujazdowskie 4, 00-478 Warsaw, Poland other plant species that were available. Mostly, these had inflorescences similar to those that were removed.

Keywords Modularity - Generalization - Food web · Nestedness · Meadow ecology $\cdot$ Network robustness

\section{Introduction}

Since the publication of the highly cited work of Jordano (1987), the number of papers addressing ecological networks has grown steadily. Yet, despite criticism by some authors and claims about the "abuse" of network metrics in describing community patterns (Blüthgen et al. 2008; Blüthgen 2010; Willmer 2011), network analyses nevertheless provide a useful tool for studying the interactions of species. Such investigations are not possible when species are studied in isolation (Blüthgen 2010). The "network approach" is particularly important at this time, when there is growing evidence that biodiversity conservation should now focus on ecological services and ecologically important taxa, rather than just on rare species (Cadotte et al. 2011; Elle et al. 2012; Montoya et al. 2012). Of the various ecological interactions, pollination seems to be an especially ubiquitous type of mutualism in most terrestrial ecosystems, involving almost $90 \%$ of all flowering plant species (Willmer 2011), and a significant fraction of invertebrate and vertebrate species, together including at least one-third of all known organisms worldwide (Kearns et al. 1998). Indeed, to date, pollination networks are among the most extensively studied ecological networks (Olesen et al. 2011).

Network analyses are already widely used for identifying species of special conservation interest (Hegland et al. 2010) or for predicting the fate of the network, following 
disturbances (Dunne et al. 2002; Memmott et al. 2004; Bascompte and Stouffer 2009; Kaiser-Bunbury et al. 2010; Quinto et al. 2012). In most cases, these analyses show that a small number of structural species (nodes that have many connections within a network) are responsible for system robustness and that the loss of these taxa and their interactions could cause a sudden collapse in the network (e.g. Kaiser-Bunbury et al. 2010, but for a somewhat different view see Memmott et al. 2004). If the above is true, i.e. network analyses can successfully predict pollination network stability, we can expect network analyses to become one of the essential steps in evaluating ecosystems for conservation purposes. This could entail the studying of, for example, generalist plants that are usually not the focus of conservation activities (Elle et al. 2012), but that form an important element of ecosystem function recovery strategies (Zych et al. 2007; Menz et al. 2011; Montoya et al. 2012)., The loss of these species may be translated, via pollinator population decline, into the pollination deficits of more peripheral species, resulting in further cascading to the rest of the network (Elle et al. 2012).

Currently, our knowledge of this aspect of network functioning is mostly based on simulations and therefore may be prone to bias owing to false assumptions (Blüthgen 2010). Most models assume that whenever a species loses its last connection, it becomes excluded from the community and disappears from a network (e.g. Yadav and Babu 2012). Thus, since the majority of published projections are derived from such empirically untested models, their value in conservation remains virtually unknown (Tylianakis et al. 2010). For example, some theoretical studies reveal considerable unsusceptibility of ecological networks and a general robustness towards species extinction (Memmott et al. 2004). Two modelling surveys also demonstrated mechanisms that protect networks against node loss, such as rewiring, i.e. behavioural shifts in the interactions between plants and pollinators (RamosJiliberto et al. 2012) or the adaptive foraging of pollinators (Valdovinos et al. 2013). However, to the best of our knowledge, only three published empirical studies addressed the effect of species loss on pollination network structure. Whereas the first investigation analysed the effect of elimination of the invasive hub plant species from a small Mediterranean community (Ferrero et al. 2013), the second investigated the loss of an important pollinator from a mountain meadow (Brosi and Briggs 2013). Although these manipulations resulted in changes to the node degree of some plants (Ferrero et al. 2013), or to the floral fidelity of their pollinators (Brosi and Briggs 2013), in both cases, the main network attributes remained almost unchanged. On the contrary, the third experiment (Lopezaraiza-Mikel et al. 2007) showed that networks lacking the hub plant contain significantly fewer insect species and thus the process of pollination is insufficient. This study demonstrated clear differences in networks before and after manipulation. It is important to note that the previously mentioned studies did not include modularity analysis. Assuming that the impact of elimination mostly affects the module around the excluded hub (Olesen et al. 2007), reorganization of the modules may reveal the way in which pollinators adjust to changes in their environment. Therefore, in order to address empirically the subject, we decided to test experimentally pollination network robustness following the removal of keystone species, by supplementing our investigation with modularity analysis. Our study was based on a temporally and taxonomically highly resolved Dipteran-dominated pollination network from a damp lowland meadow in NE Poland (Goldstein et al. unpublished), which allowed us to designate the most connected plant in a field

We were especially interested in whether the removal of the core floral resource (1) affects the availability of pollinators, i.e. whether floral visitors choose to switch to other floral resources present in the system (rewire) or depart from the network, (2) influences the modular structure of the network and (3) significantly alters basic network descriptors. The frame of reference was provided by a simple model that eliminates the desirable plant species and, consequently, unconnected nodes (see "Materials and methods" section). We anticipated that, according to the result of the model, elimination of the hub node would cause an emigration of the insects that formerly visited eliminated plant and created a module around it. Therefore, the mentioned module would shrink or disappear, but other would remain unchanged in terms of number and species composition. Moreover, we expected that connectance, modularity and network specialization values change according to the model.

\section{Materials and methods}

\section{Study area}

Our experiment was performed in a large, traditionally used, damp hay meadow complex near the village of Kleczkowo (Ostrołęka district, Mazowieckie Province, NE Poland), an area with well-preserved Molinietalia meadow vegetation rich in red-list plant species (Zych and WerblanJakubiec 2006), and free of invasive plant species. We selected two meadows measuring approx. 0.5 ha each, surrounded by shrubland/woodland vegetation and separated from each other by a 500-m-wide area of shrubs and trees. One of the meadows was designated as the experimental plot (hereafter referred to as experimental meadow) and the other as the control plot (hereafter referred to as 
control meadow). The last one was used to assess the natural variability of recorded networks. Each meadow housed 15 species of flowering plants, and 14 of them were represented in both meadows: Anthriscus sylvestris (L.) Hoffm., Campanula patula L., Cardaminopsis arenosa (L.) Hayek, Galium palustre L., Galium uliginosum L., Geum rivale L., Lychnis flos-cuculi L., Plantago lanceolata L., Polemonium caeruleum L., Polygonum bistorta L., Ranunculus repens L., Stellaria media (L.) Vill., Trifolium repens L., and Veronica chamaedrys L. Myosotis palustris Hill. were present only on control meadow, whereas $\mathrm{Va}$ leriana officinalis L. only on experimental meadow. In order to compare flowering species composition, in each plot we randomly chose 10 circles of 1-m radius along the transect, where we counted floral units (sensu Gibson et al. 2006). We distinguished between two floral units (be it a single flower or group of flowers/inflorescences), if an insect in order to move from one to the other needed to fly. Plant species composition and mean abundance of floral units were analysed with Simpson index $(D=0.199$ for control and $D=0.127$ for experimental meadow, Simpson 1949) and compared between meadows with SørensenDice coefficient $(\mathrm{QS}=0.933)$. The plots were also similar in terms of agrotechnical practices. The weather during experiment was relatively constant: about $20-22{ }^{\circ} \mathrm{C}$ with thin cloud cover and no rain or fog.

\section{Base networks}

In order to designate plant species for experimental removal, earlier in the same site, during the growing seasons in 2009 and 2010 (April-September), at fortnightly intervals, all zoogamous plant species in flower were monitored three times for $10 \mathrm{~min}$ between 10.00 and $16.00 \mathrm{~h}$ for insect visitors (we excluded Cyperaceae, Juncaceae and Poaceae). For this purpose, a patch of flowering plants of a particular species was randomly selected (we tried to avoid repeated sampling on the same patch) and all insect visitors that came into contact with the reproductive parts of the flowers were captured using an entomological net, pinned and stored dry for further identification. During sampling, we discarded any ants caught (Formicidae), because their inefficiency as pollinators is well documented (Beattie and Hughes 2002). If insect identification were possible while the insect was on the flower (e.g. in the case of bumblebees, honeybees and some butterflies), the animals were released once their identity was recorded. In most cases, insects were identified to species level, but in some ambiguous cases, to the family, genus or "morphotaxon" level. Our primary concern during identification was to distinguish between taxa in order to ensure that they could be assigned to different nodes. We constructed two pollination networks - one from 2009 and one from 2010
(Goldstein et al. unpublished). Based on modularity analysis (Olesen et al. 2007) using Netcarto (Guimera and Amaral 2005), we selected three plant species as network hubs: Angelica sylvestris L., Anthriscus sylvestris and Polygonum bistorta. For our manipulation experiment, we chose P. bistorta (hereafter Polygonum), because it was the most linked species.

\section{The experiment}

The entire experimental work was completed during the first week of June 2012, during peak flowering of Polygonum (it lasts in this area about 3 weeks). For both the control and experimental meadow, we performed the before-after method using similar collecting protocol to the one of base networks, but with one difference: observations were repeated nine times between 10.00 and $16.00 \mathrm{~h}$ for each observation day, totalling $180 \mathrm{~min}$ of observations for each of the plant species in the plot over a two day period. Identification of flower visitors was performed as described above.

For 2 days (3-4 June 2012), we recorded two pollination networks: the first in the experimental (listed below as E-before) and the other in the control (C-before) meadow.

On 5 June 2012, we removed all Polygonum inflorescences (ca. 8000) from the experimental meadow. For two consecutive days (6-7 June 2012), we recorded pollination networks in both experimental and control meadows (now called E-after and C-after). Recording of the four networks needed concentrated sampling effort to make them comparable.

\section{Data analysis}

Our observations were organized as adjacency matrices $\left[a_{i j}\right]$ showing interacting species, where $a_{i j}=$ number of interactions between $i$ plant species (taxon) and $j$ floral visitor species (taxon), separately for each of the four networks (Ebefore, E-after, C-before, C-after). Plant species with no recorded visitors were excluded from the current matrix in order to avoid creating unconnected nodes, and only connectance analyses were undertaken using those plants. In order to compare our results with our theoretical predictions of network disturbances, we also performed a simulation of $P$. bistorta node removal from E-before using Nexcade (Yadav and Babu 2012), creating the fifth matrix (E-nexcade). Nexcade software is used to visualize graphs, show their base metrics and perform simple perturbations like deleting nodes or links from a network. Therefore, the difference between E-nexcade and E-before involves only the eliminated node, its links and nodes disconnected with the network through the elimination.

For each of the above matrices, we calculated connectance (including plant species without any visit), 
modularity and specialization. For all matrices, we performed modularity analysis using Netcarto (Guimera and Amaral 2005) with the parameters advised by the authors. The results of the modularity analysis were tested against 100 randomly obtained networks. Following Olesen et al. (2007), the species were assigned to four different network roles (peripherals, connectors, module hubs and network hubs), depending on their $z$ (within module degree) and $c$ (among-module connectivity) scores derived from modularity analysis: $c \leq 0.62$ and $z \leq 2.5$ classify a node to peripherals; $c>0.62$ and $z \leq 2.5$-to connectors; $c \leq 0.62$ and $z>2.5$-to module hubs; $c>0.62$ and $z>2.5$ - to network hubs. In order to assess the specialization of our networks, we calculated standardized frequency-based indices $\mathrm{H}_{2}{ }^{\prime}$ (Blüthgen et al. 2006) against 10,000 random matrices (null model created by the software). Null model analysis for modularity and specialization are presented by standard scores according to the equation $Z=(x-\mu) / \sigma$, where $x$ is observed value, $\mu$ is mean value of proper null model and $\sigma$ is standard deviation. Standard scores higher than 1.67 or lower than -1.67 show that estimated value is significantly higher or lower (respectively) than the one from the proper null model.

\section{Results}

\section{Before the experiment}

Our initial focus networks were composed of $11+64$ and $11+52$ nodes (plant + insect species, Table 1), linked with 94 and 83 relations that were established by 150 and 111 interactions, respectively, for the control (C-before) and experimental meadow (E-before). Connectance was greater in the larger C-before network (0.098) compared to the other (0.091). Both networks were also modular (respectively, 0.58 and 0.53 for C-before and E-before) and consisted of seven and six modules (Fig. 1) developed around five and four hub plant species (respectively, $A n$ thriscus sylvestris, P. bistorta, Veronica chamaedrys, Ranunculus repens, and Lychnis flos-cuculi for C-before; Anthriscus sylvestris, P. bistorta, Cardaminopsis arenosa and L. flos-cuculi for E-before) and several non-hub plant nodes. Both matrices were moderately specialized, with E-before being slightly more generalized than C-before $\left(H_{2}{ }^{\prime}=0.409\right.$ and 0.460 , respectively).

\section{After the experiment}

After removing Polygonum inflorescences the size of both networks from the control and experimental meadow diminished. Though more plant species were visited (relative change $\mathrm{RC}=0.18$ and 0.09 , respectively, for control and experimental meadow), less insect species appeared (as above, $\mathrm{RC}=-0.09$ and -0.04$)$, established fewer relations (as above, $\mathrm{RC}=-0.16$ and -0.12 ) and had fewer interactions with flower species (as above, $\mathrm{RC}=-0.26$ and -0.25 ). Such reduction was followed by connectance (as above, $\mathrm{RC}=-0.07$ and -0.08 ). After manipulation, only 31 and $33 \%$ of the insect taxa that were recorded before the removal of inflorescences reappeared on the control and experimental fields, respectively (see ESM
Table 1 Metrics of recorded networks, including that of the Nexcade manipulation

\begin{tabular}{llllll}
\hline & C-before & C-after & E-before & E-after & E-nexcade \\
\hline No. of visited plant species $(i)$ & 11 & 13 & 11 & 12 & 10 \\
No. of insect taxa $(j)$ & 64 & 58 & 52 & 50 & 49 \\
(No. of $P$. bistorta visitors) & 19 & 23 & 20 & 12 & 17 \\
No. of relations & 94 & 79 & 83 & 73 & 69 \\
(relations of $P$. bistorta visitors) & 36 & 30 & 42 & 19 & 28 \\
No. of interactions $\left(\Sigma a_{i j}\right)$ & 150 & 111 & 121 & 91 & 94 \\
(interactions of $P$. bistorta visitors) & 68 & 47 & 64 & 23 & 37 \\
Connectance & 0.098 & 0.091 & 0.106 & 0.098 & 0.094 \\
Modularity $(Q)$ & 0.58 & 0.66 & 0.53 & 0.61 & 0.58 \\
$\quad$ Standard score & $\mathbf{3 . 2 9}$ & $\mathbf{4 . 2 8}$ & $\mathbf{1 . 8 0}$ & $\mathbf{3 . 2 8}$ & $\mathbf{2 . 7 7}$ \\
Network specialization $\left(H_{2}{ }^{\prime}\right)$ & 0.460 & 0.465 & 0.409 & 0.286 & 0.34 \\
Standard score & $\mathbf{- 9 . 5 6}$ & $\mathbf{- 5 . 7 9}$ & $-\mathbf{5 . 3 1}$ & $\mathbf{- 1 . 8 2}$ & $\mathbf{- 2 . 8 9}$ \\
\hline
\end{tabular}

Modularity of higher values characterize more modular network. $H_{2}{ }^{\prime}=$ standardized value of two-dimensional Shannon entropy (take values from 0 to 1.0: from extreme generalization to perfect specialization). Standard scores of modularity likewise two-dimensional Shannon entropy were calculated according to the equation $Z=(x-\mu) / \sigma$, where $x$ is observed value, $\mu$ is mean value of proper null model and $\sigma$ is standard deviation. Standard scores higher than 1.67 or lower than -1.67 (written in bold) show that estimated value is significantly higher or lower (respectively) than the one from the proper null model at $\alpha=0.05$ 


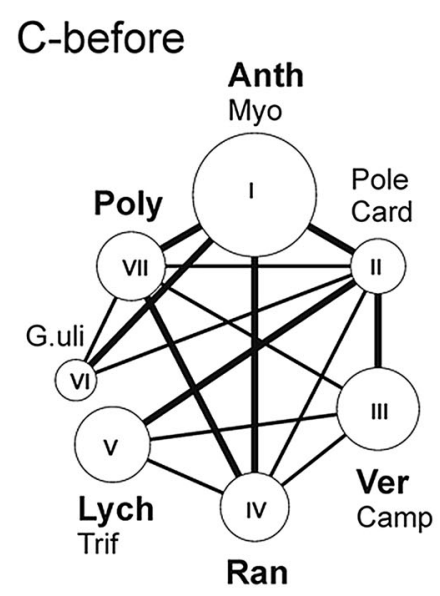

\section{E-before}

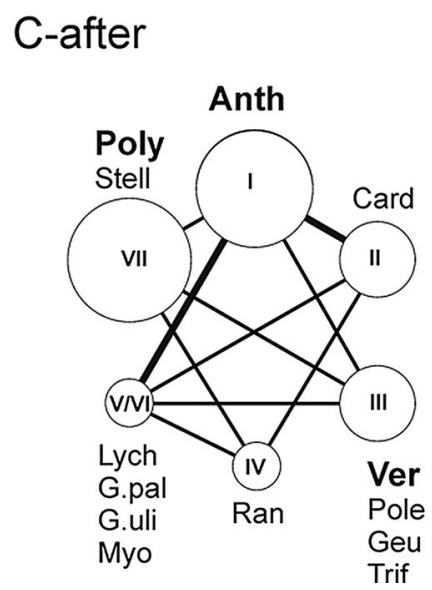

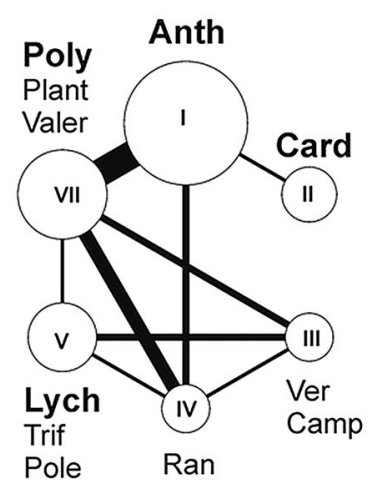

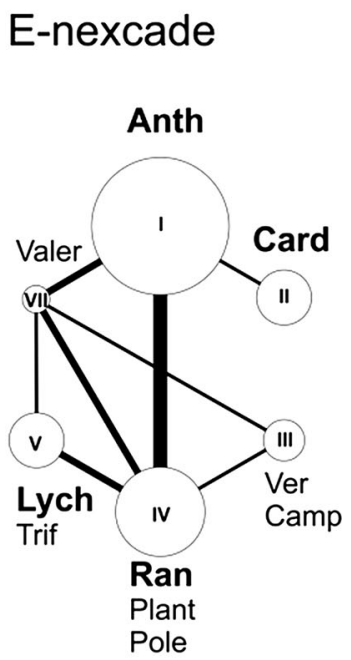

Fig. 1 Graphs represent recorded networks with shrunken modules (all nodes in a module are fused into one vertex) according to the modularity analysis performed using Netcarto program (Guimera and Amaral 2005). Circle radius is proportional to the number of species forming a particular module; the thickness of lines is proportional to the number of interactions between modules. Abbreviations denote plant species grouped in a module (names in bold correspond to plant nodes designated as hubs): Anth-Anthriscus sylvestris (L.) Hoffm, Camp—Campanula patula L., Card-Cardaminopsis arenosa (L.)

Appendix). Both networks remained modular with even higher values of modularity (as above, $\mathrm{RC}=0.14$ and $0.15)$, but the number of modules in the control field decreased and in both networks only three hubs were revealed (Fig. 1). Furthermore, the identity of some plant species acting as hub nodes changed (Anthriscus sylvestris, Polygonum and V. chamaedrys for C-after; Anthriscus sylvestris, Plantago lanceolata and L. flos-cuculi for E-after). Plantago lanceolata (hereafter Plantago) was the only plant species to become a hub plant (after being peripheral) following the manipulation. This plant showed the greatest relative change among $z$ values between -before and -after networks (see ESM Appendix, Table 6). Differences in the composition of insect orders between corresponding modules (formed around the same plant

species) were moderately similar, but the modules around L. flos-cuculi and Polygonum/Plantago differed across the sites (see ESM Appendix). This network, E-after, became also the most generalized $\left(H_{2}{ }^{\prime}=0.286, \mathrm{RC}=-0.30\right)$, while the other remained almost unchanged $\left(H_{2}{ }^{\prime}=0.465\right.$, $\mathrm{RC}=0.01)$.

The Nexcade network contained one plant and three insect species fewer than E-before, which following manipulation lost the last connection. The difference from E-before included a slight decrease in connectance $(\mathrm{RC}=-0.11)$. Six modules were registered at the modularity level of $0.58(\mathrm{RC}=0.09)$, four of them around plant hubs (A. sylvestris, C. arenosa, $R$. repens and L. flos-cuculi), whereas specialization level decreased to $H_{2}{ }^{\prime}=0.34$ $(\mathrm{RC}=-0.17)$. 
Roman numerals that describe modules in all matrices (Fig. 1) were added after the most connected plant species in a module: I-the module with $A$. sylvestris, II-with $C$. arenosa, III-with $V$. chamaedrys/Campanula patula, IV-with $R$. repens, V-with L. flos-cuculi, VI-with Galium uliginosum, VII-with P. bistorta./Plantago lanceolata L. All mentioned values of modularity and specialization level were significantly different from the values obtained from the proper null models at $\alpha=0.05$.

Insects that were recorded on $P$. bistora during the whole experiment (Table 1) were almost equally diverse on both meadows before manipulation (control meadow: 19 species establish 36 relations with 68 interactions; experimental meadow: 20 species, 30 relations and 64 interactions). After removing of $P$. bistorta, we recorded slightly more species from this group (RC: 0.21 ), but they had less relations and interactions ( $\mathrm{RC}$ : -0.17 and -0.31 , respectively) on control meadow. Conversely, this group diminishes its richness (RC: -0.40) and strongly reduces the number of relations and interactions (RC: -0.55 and -0.64 , respectively) in the experimental meadow.

Summarizing all four networks, we obtained a list of 16 plant species (37 and 69\% were recorded before earlier in the same period of year 2009 and 2010, respectively) and 141 insect species (20 and $25 \%$ recorded before, as above) that established 254 interactions ( 25 and $36 \%$ recorded before, as above). Other results, i.e. characteristics of all nodes in matrices including $z$ - and $c$ values (tab. 3.), remaining measurements of the five matrices (tab. 4.), core insect species and its module suborder (tab. 5.), relative changes between before and after experiment of $z$ - and $c$-values computed for plant species (tab. 6.) and whole structure of the four matrices (tab. 7., 8., 9., 10. and 11.), which are less important for interpretation of our experimental manipulation, are presented in the ESM Appendix.

\section{Discussion}

Here, we present the results of the experimental manipulation of a pollination network, in which the removed plant resources were selected on the basis of a long-term, 2-yearsampling of the visitation network of a lowland meadow. Although our experiment lasted only 1 week, we sampled relatively extensively prior to and following the experimental removal of plants (in total $2880 \mathrm{~min}$ of observations over 4 days of study). Surprisingly, all four recorded networks, including those from the very same meadow, differed greatly from each other in terms of species composition. Although plant species were almost identical, only about one-third of insect taxa reappeared in the same meadow.
Many authors have predicted that the loss of a hub would cause secondary extinctions due to broken links, which are essential for the existence of pollinators or plants (Dunne et al. 2002; Bascompte and Stouffer 2009; KaiserBunbury et al. 2010; Quinto et al. 2012). In our case, this would be caused by a prevailing insect emigration over immigration into the experimental field. Taking into account all insect species, this did not occur, as their number diminished in both meadows. On the other hand, insects that used to visit Polygonum inflorescences would suffer the most due to our manipulation. If we exclude all but the Polygonum visitors, their abundance became strongly reduced as well as the number of established relations and interactions (Table 2). Probably some insects that respond to the Polygonum flowering syndrome emigrated and became replaced by insect immigrants. However, since the presence of a given species is driven by multiple agents, and most of those are beyond our control, we cannot identify for certain exactly which absence is caused by hub elimination. Probably better control of the system and extension of the experiment duration would allow to resolving this problem. Similarly, considering that the weather was relatively constant, we cannot explain what exactly drove the reduction in insect species and interactions in both meadows during the experiment.

Contrary to our hypothesis, all registered networks contained six or seven modules and were significantly modular without any trends that would reveal the effect of manipulation. Both values of modularity increased to the same extent, probably as an effect of natural variability. Like the results of Dupont and Olesen (2009), our modules were moderately similar across sites: most were formed around the same plant species, which often performed a hub role. The position of other plant nodes in a module was usually more labile, and this may be responsible for strong variation in pollinator assemblage between modules in networks (e.g. insects in the module of L. flos-cuculi). We also observed changes in the number of modules in the control field (Fig. 1), where two modules (V and VI, created around G. uliginosum and L. flos-cuculi) merged during the course of the experiment.

With regard to plant nodes, the most striking difference was observed in the E-after network, where a new module of Plantago was recorded. This plant had not previously been reported as a hub in that site (Goldstein et al. unpublished). It was also a peripheral (or excluded from the network with no insect visits) in all networks except for E-after. In E-before, Plantago co-created the Polygonum module (Fig. 1), but when in E-after, it became a hub species and partly replaced the absent Polygonum (some insects that had interactions with Plantago in E-after had previously visited inflorescences of Polygonum; see ESM Appendix). A similar phenomenon was reported by Tarrant 
Table 2 Relative changes (RC) between values that characterize recorded networks (presented in Table 1): $\mathrm{RC}=\left(x-x_{\mathrm{ref}}\right) / x$, where $x$ concerns values after manipulation and $\mathrm{x}_{\mathrm{ref}}$ concerns values before manipulation

\begin{tabular}{lccc}
\hline Relative change between & C-before \& C-after & E-before \& E-after & E-before \& E-nexcade \\
\hline No. of plant species $(i)$ & 0.18 & 0.09 & -0.09 \\
No. of insect taxa $(j)$ & -0.09 & -0.04 & -0.06 \\
(No. of $P$. bistorta visitors) & 0.21 & -0.40 & -0.15 \\
No. of relations & -0.16 & -0.12 & -0.17 \\
(established by $P$. bistorta visitors) & -0.17 & -0.55 & -0.33 \\
No. of interactions $\left(\Sigma a_{i j}\right)$ & -0.26 & -0.25 & -0.22 \\
(these of $P$. bistorta visitors) & -0.31 & -0.64 & -0.42 \\
Connectance & -0.07 & -0.08 & -0.11 \\
Modularity $(Q)$ & 0.14 & 0.15 & 0.09 \\
Network specialization $\left(H_{2}{ }^{\prime}\right)$ & 0.01 & -0.30 & -0.17 \\
\hline
\end{tabular}

and Ollerton (unpublished). In their survey, the most connected plant Centaurea nigra L. after similar removal became replaced by Knautia arvensis (L.) Coult. In both cases, the observed exchange of taxa could perhaps be explained in terms of similar inflorescence structure and the similar floral display characteristics of these species. In our study, Plantago and Polygonum produced vertical spikes that were densely packed with relatively small, pink (Polygonum) or white-pinkish (Plantago) flowers, which may resemble each other from the pollinators perspective. This process was partly predicted by the model of RamosJiliberto et al. (2012), where the best choice for pollinators following plant elimination was to replace the lost host with the nearest plant in terms of network topology. However, given that some other insects from the Plantago module were "sucked in" from the module of L. flos-cuculi and $V$. chamaedrys (they changed modules after manipulation, see ESM Appendix), in our case it was not merely a simple replacement, but to some extent, the creation of a new element in the E-after network. The best explanation for such variability of pollinator assemblage across modules is provided by the theory of rewiring, as this process is known to increase network robustness (Ramos-Jiliberto et al. 2012). The insect assemblage, following elimination of Polygonum, became connected to the available set of flowering plants, and this resulted once more in the creation of the nested structure. Given that the number of insect taxa is almost identical, it is possible that the reorganization of the network occurs in two ways. Plantago might replace Polygonum or other plants present in the network might receive more insect visitors according to the "rich-gets-richer" rule (Bascompte and Jordano 2007). In our case, probably both of these processes occurred to some extent.

According to our expectations, the removal of the core plant resources also resulted in a decline in the specialization level of the E-after network. This measure is known to be less affected by sampling bias (Blüthgen et al. 2006). In our control meadow, it remained unchanged, but diminished in experimental meadow, indicating that the E-after network was more generalized than the E-before network (Table 1). Contrary to our hypothesis, this effect did not happen because of the decrease in insect number but through the change of behaviour of the insect assemblage. This situation is congruent with the fact that the experimental field had been altered by our manipulation and that changes to the environment favours generalists. Probably, the elimination of the main source of food forced the local insect community to leave their specialized preferences and seek different plant-hosts.

The network resulting from Nexcade modelling resembled the result obtained for the experiment (E-after) in number of insect taxa and specialization level, and all properties of $P$. bistorta visitors, which decreased according to the trend. Interestingly, the number of relations, connectance and modularity were higher in E-after than predicted by the model. Such result might emerge from pollinators' rewiring. The model network also contained six modules-the Polygonum module shrunk and included only Valeriana officinalis (Fig. 1), whereas Plantago (peripheral) was "sucked" into the module of $R$. repens. Although the simulation of a node collapse performed using Nexcade (Yadav and Babu 2012) correctly predicted some trends, especially the reduction of the removed plant visitors, it differed from our experimental results. The most likely reason of this difference is that the model developed by these authors did not include temporal variability of the network. Moreover, the model detects secondary extinctions whenever a node loses the last link to a network, whereas species rewiring prevents such extinctions.

As postulated by Olesen et al. (2007), modular networks should be robust against hub plant elimination because a disrupting signal spreads quickly within the module, but slowly between modules. In our experiment, the disrupted module did not disappear or fragment. Instead, it persisted, showing that certain biological factors bound the species together in one module. One of the most likely explanations is that the insect has preferences for some of the floral 
functional traits shared by both Polygonum and Plantago, which may act as a structuring mechanism in mutualistic networks (Junker et al. 2013). This may, in turn, confirm the concept of Dupont and Olesen (2009), who considered modules as coevolutionary units.

Short-term pollination studies may be strongly affected by, for example, unpredictable changes in weather condition such as wind, humidity or cloud cover (Willmer 2011), and these could also have affected our results. However, throughout the whole experiment, the weather remained unchanged, and changes in the metrics of our networks were clearly directional: both "-after" networks showed a similar reduction in the number of species, interactions and consequently connectance. Our investigation did not show any significant changes in other criteria due to elimination of a hub plant, and each difference between networks from the experimental meadow was reflected by a corresponding difference in networks from the control meadow (see ESM Appendix).

The number of network studies is steadily growing, and the value of the network approach in studies of mutualistic relationships is widely acknowledged. However, experimental work that would verify the theoretical predictions is still lacking. Our experiment showed that, contrary to the opinions of some authors (Dunne et al. 2002; Bascompte and Stouffer 2009; Kaiser-Bunbury et al. 2010; Quinto et al. 2012), pollination networks can be robust to short-term disturbances. Such ecological redundancy of networks appeared also in some experimental surveys (Ferrero et al. 2013; Brosi and Briggs 2013; Tarrant and Ollerton unpublished). One of the reasons for this robustness is perhaps the large temporal variability in pollination networks resulting from the considerable ecological plasticity of interaction identity (Petanidou et al. 2008). The alteration of the network studied by Lopezaraiza-Mikel et al. (2007) might have been caused by the simple emigration of insects to the control area or even outside the study site. As a result, the local pollinator community would not have been forced to adjust to the new conditions (which is probably what happened in our case). We conclude that there are two possible responses to local disturbances: if the main source of nectar is close, emigration is the easiest response, but if host plants are distant, it is easier for the insects to change their preferences to the most similar plant.

Since our experiment can be considered too short to reveal more fundamental changes to the network structure, it is premature to draw further conclusions about the predictive value of some network metrics and models, and more analogous long-term experiments are needed. We feel confident, however, that the comparison of real networks with their mathematical models will move us closer to understanding the processes which govern the formation and persistence of mutualistic networks.
Acknowledgments We thank landlord Ryszard Gocłowski of Kleczkowo village for helping with the field experiment, Andrzej Grzywacz (Nicolaus Copernicus University in Touń) and Piotr Tykarski (University of Warsaw) for help in insect identification. This study was financially supported by the Polish Ministry of Science and Higher Education via the Faculty of Biology, University of Warsaw intramural Grant BW 501/86-102314 to JG and via Polish National Science Centre research Grant N N304 367938 to MZ.

\section{Compliance with ethical standards}

Conflict of interest The authors declare that they have no conflict of interest.

Open Access This article is distributed under the terms of the Creative Commons Attribution 4.0 International License (http://crea tivecommons.org/licenses/by/4.0/), which permits unrestricted use, distribution, and reproduction in any medium, provided you give appropriate credit to the original author(s) and the source, provide a link to the Creative Commons license, and indicate if changes were made.

\section{References}

Bascompte J, Jordano P (2007) Plant-animal mutualistic networks: the architecture of biodiversity. Annu Rev Ecol Evol Syst 38:567-593. doi:10.1146/annurev.ecolsys.38.091206.095818

Bascompte J, Stouffer DB (2009) The assembly and disassembly of ecological networks. Philos Trans $\mathrm{R}$ Soc $\mathrm{B}$ Biol Sci 364:1781-1787. doi:10.1098/rstb.2008.0226

Beattie AJ, Hughes L (2002) Ant-plant interactions. In: Herrera CM, Pellmyr O (eds) Plant-animal interactions: an evolutionary approach. Wiley-Blackwell, New York

Blüthgen N (2010) Why network analysis is often disconnected from community ecology: a critique and an ecologist's guide. Basic Appl Ecol 11:185-195. doi:10.1016/j.baae.2010.01.001

Blüthgen N, Menzel F, Blüthgen N (2006) Measuring specialization in species interaction networks. BMC Ecol 6:9

Blüthgen N, Fründ J, Vázquez DP, Menzel F (2008) What do interaction network metrics tell us about specialization and biological traits. Ecology 89:3387-3399

Brosi BJ, Briggs HM (2013) Single pollinator species losses reduce floral fidelity and plant reproductive function. Proc Natl Acad Sci 110:13044-13048. doi:10.1073/pnas.1307438110

Cadotte MW, Carscadden K, Mirotchnick N (2011) Beyond species: functional diversity and the maintenance of ecological processes and services: functional diversity in ecology and conservation. J Appl Ecol 48:1079-1087. doi:10.1111/j.1365-2664.2011. 02048.x

Dunne JA, Williams RJ, Martinez ND (2002) Network structure and biodiversity loss in food webs: robustness increases with connectance. Ecol Lett 5:558-567. doi:10.1046/j.1461-0248. 2002.00354.X

Dupont YL, Olesen JM (2009) Ecological modules and roles of species in heathland plant-insect flower visitor networks. J Anim Ecol 78:346-353. doi:10.1111/j.1365-2656.2008.01501.x

Elle E, Elwell SL, Gielens GA (2012) The use of pollination networks in conservation. Botany 90:525-534

Ferrero V, Castro S, Costa J et al (2013) Effect of invader removal: pollinators stay but some native plants miss their new friend. Biol Invasions 15:2347-2358. doi:10.1007/s10530-013-0457-4

Gibson RH, Nelson IL, Hopkins GW et al (2006) Pollinator webs, plant communities and the conservation of rare plants: arable 
weeds as a case study: pollinator webs and rare plant conservation. J Appl Ecol 43:246-257. doi:10.1111/j.1365-2664.2006. 01130.x

Guimera R, Amaral LAN (2005) Functional cartography of complex metabolic networks. Nature 433:895-900. doi:10.1038/ nature 03288

Hegland SJ, Dunne J, Nielsen A, Memmott J (2010) How to monitor ecological communities cost-efficiently: the example of plantpollinator networks. Biol Conserv 143:2092-2101. doi:10.1016/ j.biocon.2010.05.018

Jordano P (1987) Patterns of mutualistic interactions in pollination and seed dispersal: connectance, dependence asymmetries, and coevolution. Am Nat 129:657-677

Junker RR, Blüthgen N, Brehm T et al (2013) Specialization on traits as basis for the niche-breadth of flower visitors and as structuring mechanism of ecological networks. Funct Ecol 27:329-341. doi:10.1111/1365-2435.12005

Kaiser-Bunbury CN, Muff S, Memmott J et al (2010) The robustness of pollination networks to the loss of species and interactions: a quantitative approach incorporating pollinator behaviour. Ecol Lett 13:442-452. doi:10.1111/j.1461-0248.2009.01437.x

Kearns CA, Inouye DW, Waser NM (1998) Endangered mutualisms: the conservation of plant-pollinator interactions. Annu Rev Ecol Syst 29:83-112

Lopezaraiza-Mikel ME, Hayes RB, Whalley MR, Memmott J (2007) The impact of an alien plant on a native plant-pollinator network: an experimental approach. Ecol Lett 10:539-550. doi:10.1111/j.1461-0248.2007.01055.x

Memmott J, Waser NM, Price MV (2004) Tolerance of pollination networks to species extinctions. Proc R Soc B Biol Sci 271:2605-2611. doi:10.1098/rspb.2004.2909

Menz MHM, Phillips RD, Winfree R et al (2011) Reconnecting plants and pollinators: challenges in the restoration of pollination mutualisms. Trends Plant Sci 16:4-12. doi:10.1016/j.tplants. 2010.09.006

Montoya D, Rogers L, Memmott J (2012) Emerging perspectives in the restoration of biodiversity-based ecosystem services. Trends Ecol Evol 27:666-672. doi:10.1016/j.tree.2012.07.004

Olesen JM, Bascompte J, Dupont YL, Jordano P (2007) The modularity of pollination networks. Proc Natl Acad Sci 104:19891-19896
Olesen JM, Dupont YL, Hagen M et al (2011) Structure and dynamics of pollination networks: the past, present, and future. In: Patiny $S$ (ed) Evolution of Plant-Pollinator Relationships. Cambridge University Press, Cambridge, pp 374-391

Petanidou T, Kallimanis AS, Tzanopoulos J et al (2008) Long-term observation of a pollination network: fluctuation in species and interactions, relative invariance of network structure and implications for estimates of specialization: high plasticity in plantpollinator networks. Ecol Lett 11:564-575. doi:10.1111/j.14610248.2008.01170.x

Quinto J, Marcos-Garcia MA, Diaz-Castelazo C et al (2012) Breaking down complex saproxylic communities: understanding subnetworks structure and implications to network robustness. PLoS One. doi:10.1371/journal.pone.0045062

Ramos-Jiliberto R, Valdovinos FS, Moisset de Espanés P, Flores JD (2012) Topological plasticity increases robustness of mutualistic networks: interaction rewiring in mutualistic networks. J Anim Ecol 81:896-904. doi:10.1111/j.1365-2656.2012.01960.x

Simpson EH (1949) Measurement of diversity. Nature 163:688

Tylianakis JM, Laliberté E, Nielsen A, Bascompte J (2010) Conservation of species interaction networks. Biol Conserv 143:2270-2279. doi:10.1016/j.biocon.2009.12.004

Valdovinos FS, Moisset de Espanés P, Flores JD, Ramos-Jiliberto R (2013) Adaptive foraging allows the maintenance of biodiversity of pollination networks. Oikos 122:907-917. doi:10.1111/j. 1600-0706.2012.20830.x

Willmer P (2011) Pollination and floral ecology. Princeton University Press, Princeton

Yadav G, Babu S (2012) NEXCADE: perturbation analysis for complex networks. PLoS One 7:e41827. doi:10.1371/journal. pone.0041827

Zych M, Werblan-Jakubiec H (2006) Nowe stanowisko Betula humilis (Betulaceae) na północno-wschodnim Mazowszu. Fragm Florist Geobot Pol 12:171-173

Zych M, Niemczyk P, Niemirski R (2007) Umbellifers as potential keystone species in restoration projects. Acta Agrobot 60:45-49 